\title{
Estimation of genetic trends from 1977 to 1998 for farrowing characteristics in the French Large White breed using frozen semen
}

\author{
L. Canario ${ }^{1 \dagger}$, L. Rydhmer ${ }^{2}$, J. Gogué ${ }^{3}$, T. Tribout ${ }^{1}$ and J. P. Bidanel ${ }^{1}$ \\ ${ }^{1}$ INRA UR337 Station de Génétique Quantitative et Appliquée, F-78352 Jouy-en-Josas, France; ${ }^{2}$ Department of Animal Breeding and Genetics, Swedish University \\ of Agricultural Sciences, Box 7023, S-750 07 Uppsala, Sweden; ${ }^{3}$ INRA UE332 Domaine Expérimental de Bourges, F-18300 Osmoy, France
}

(Received 16 November 2006; Accepted 5 June 2007)

\begin{abstract}
The objective of the study was to estimate genetic trends from 1977 to 1998 in the French Large White (LW) breed for stillbirth and associated traits measured at farrowing using frozen semen. Two groups of pigs (G77 and G98) were obtained by inseminating LW sows with semen from LW boars born either in 1977 or in 1998. A second generation was produced by inter se mating in each group. Farrowing was thoroughly supervised through both direct observations and video recording all long farrowing on a total of 137 first- and second-parity litters produced by sows from this second generation (68 G77 and 69 G98 litters, respectively). Measurements included birth time, weight and birth characteristics (including orientation, presence of cyanosis or oedema, membrane obstruction, umbilical cord length/content) of each piglet, as well as sow traits (weight and backfat thickness, farrowing duration, litter size and within-litter variation of weights at birth). The data were analysed using linear or generalised linear mixed models, according to the definition of the trait (continuous or binary data). The importance of several effects to piglet probability of stillbirth was then quantified by computing the reduction of variance associated with the addition of each effect in the model. Litter size did not significantly differ in first parity, but was higher in G98 second-parity sows: the differences for global (including pre partum dead piglets) and total numbers of piglets born per litter were $+2.3 \pm 1.1$ and $+1.3 \pm 0.6$, respectively. G98 sows also had a higher number of stillbirths in both parities $(+0.7 \pm 0.3$ stillborn per litter). Piglets from 698 litters were heavier at birth $(+130 \pm 40 \mathrm{~g}$ for birth weight adjusted for litter size), without any increase in within-litter heterogeneity of birth weight. No significant difference was detected between G77 and G88 groups for farrowing length and the distribution of time interval between piglet births. G98 stillborn piglets had longer and more often empty umbilical cords at birth. G98 piglets born alive also had more often umbilical nodes than $G 77$ piglets. These characteristics were considered as indicators of increased farrowing difficulties and risk of hypoxia at birth in G98 pigs. Time of birth of each piglet, sow fatness at farrowing and time of first placenta expulsion were the main factors of variation of the piglet's probability of stillbirth.
\end{abstract}

Keywords: farrowing, genetic trend, hypoxia, pigs, stillbirth

\section{Introduction}

Like many commercial pig populations in the world, the French Large White (LW) breed has been selected for several decades to improve growth efficiency and carcass lean content (Bidanel et al., 2005). Since the early 1990s, litter size has become a major element of the LW overall selection goal and has been successfully selected through 'hyperprolific' selection schemes, the use of best linear unbiased prediction (BLUP) animal model and artificial

${ }^{\dagger}$ E-mail: laurianne.canario@jouy.inra.fr insemination. This improvement has unfortunately been accompanied by an increase in perinatal and, to a lesser extent, birth to weaning mortality.

The adverse effects of selection are often difficult to reveal, as corresponding traits are not routinely recorded in breeding programmes. As suggested by Smith (1977), the use of stored gametes or embryos is an elegant way of measuring genetic trends for a large number of traits. It is complementary to estimations obtained from purely statistical approaches such as the computation of breeding values with BLUP animal models, which are easy to obtain, but are limited to routinely recorded traits. Moreover, 
contrary to BLUP animal model estimates, results are independent of the genetic parameters of the population. The principle of this methodology is to use frozen material to produce animals that are representative of the population at the beginning of the selection process and compare them with a population sample after selection. This approach was used by Tribout et al. (2001 and 2003) to estimate genetic trends in the French LW breed from 1977 to 1998. Results showed an increase of 2.9 piglets born per litter, of which 0.8 were additional stillbirths (Tribout et al., 2003). The causes of this deterioration of farrowing survival remain poorly known. It may be due to a higher risk of hypoxia resulting from uterine contractions that reduce oxygenation of the unborn piglets, early placenta detachments, or damage or premature ruptures of the umbilical cords. Such disturbances are more frequent in large litters (Herpin et al., 1996; Alonso-Spilsbury et al., 2005). Several studies have demonstrated the important association between farrowing kinetics (duration and rhythm) and stillbirth (e.g. Fahmy and Flipot, 1981; Fraser et al., 1997; Canario et al., 2006a; Pedersen et al., 2006). Birth weight is another major component of farrowing survival (Knol et al., 2002b; Canario et al., 2006a). The experiment of Tribout et al. (2003) was extended to a second generation of sows in order to investigate more thoroughly the different causes of increased pre-weaning piglet mortality and their relationships with sow maternal abilities. The objective of this study was to estimate genetic trends for traits measured at farrowing using the frozen semen methodology proposed by Smith (1977).

\section{Material and methods}

\section{Experimental design, animal management and data recording}

Two genetic groups of animals (referred to as G77 and G98) have been produced by inseminating French LW sows with semen from boars born either in 1977 or in 1998 (Tribout et al., 2003). Three generations of $\mathrm{G} 77$ and $\mathrm{G} 98$ pigs were then produced by inter se mating of randomly chosen $\mathrm{G} 77$ or $\mathrm{G} 98$ boars and gilts. The current experiment used $38 \mathrm{G} 77$ and $40 \mathrm{G} 98$ randomly selected females from the secondgeneration and their litters produced in the INRA experimental herd of Bourges (Cher). Sows were inseminated twice at a 12-h interval with the semen of boars from the same genetic group. Due to some delay in the production of second-generation boars, gilts were inseminated with frozen semen from first-generation boars for their first parity. Fresh semen was used for second-parity litters as secondgeneration boars became available and the amount of frozen semen still available was insufficient. Sow and litter characteristics at birth were recorded from August 2003 to September 2004.

Animals were tethered during gestation. Their body composition (body weight and fatness) was measured before entering the farrowing unit (approx. 1 week before the expected date of farrowing). Sows were managed in a batch-farrowing system, with a 3-week interval between successive batches. They were fed 2.5 to $3 \mathrm{~kg}$ commercial sow diet twice daily during the whole gestation period. Each farrowing unit contained 20 individual crates but was not always filled. As often as possible, G77 and G98 sows were placed in neighbouring farrowing crates (a G77 female had G98 neighbour sows). Sows were housed on partially slatted floor covered with a thin layer of straw. Crates were separated with a low wall $(50 \mathrm{~cm}$ high), so that sows could see at least their neighbours. The room was permanently illuminated, and also received natural light. Feed was distributed at 0800 and $1630 \mathrm{~h}$ and sows had free access to water with a low-pressure nipple drinker. Farrowing was not induced and birth-assistance treatments (oxytocin and vaginal palpation) were performed only in cases of extreme necessity involving sow survival. Three G77 and four G98 sows were treated during the whole study. From day 111 of gestation, animals were monitored daily to identify signs of impending parturition (milk let down, vulvar swelling and mucous secretion). Another aim of these visits was to reduce their apprehension towards human presence. Sow parturition was observed continuously in 98 of the 137 farrowings. This was facilitated by video supervision from an adjacent room. The onset of farrowing was considered as missing if the first piglet(s) born was (were) dry when seen for the first time and if more than two piglets were observed at the first visit. Piglet birth time and order were individually recorded. Each expelled piglet was immediately caught. Its umbilical cord was cut and a blood sample taken for physiological studies (Canario et al., 2005). The remaining part of the umbilical cord was ligatured with a surgical silk. Subsequently, the piglet was brought to an 'intervention place', away from the parturient sow but located inside the maternity, to be dried with straw and drying paper, weighed, sexed and marked on its back with a number corresponding to its birth order. Apart from these manipulations that may stimulate newborn vitality, avoidance of any interference with the natural delivery of the piglets was aimed at. For instance, there was no human intervention to control aggression toward newborns or to avoid crushing, and piglets were not assisted to find a teat. Only piglets blocked in their foetal membranes and about to die from asphyxia were helped. The limitations and non-interventions mentioned above permitted to appreciate the biological phenomenon as objectively as possible. Although restricted, care was provided to the animals when essential to respect the general guidelines outlined in the European animal welfare regulations.

At farrowing, two classes of piglets born dead are commonly defined: pre partum deaths, corresponding to mummified piglets and piglets dying before onset of partum (macerated piglets), and intra-partum deaths associated with intrauterine hypoxia and dystocia (Svendsen et al., 1986). These intra-partum deaths will be referred to as 'stillbirth' hereafter, in accordance with Christianson (1992). Thanks to intensive supervision, piglet stillbirth could be 
precisely defined and determined: a stillborn was an apparently full-term foetus that made no visible movement after birth. All piglets recorded as stillborn were deep frozen for later examination. Two series of post mortem examinations were realised on thawed piglets, including the lung flotation test (Sims and Glastonburry, 1996). Among the 142 piglets that were assumed stillborn, 128 were dissected post mortem. Five piglets were misclassified and then correctly classified as born-alive piglets. Prenatal deaths, including mummified and pre partum stillborn piglets (fully developed piglets, with signs of deterioration) were also counted. Different criteria, reviewed by Alonso-Spilsbury et al. (2005), are associated with stillbirth and birth difficulties. Among those, we chose the criteria described in Table 1: related to death due to hypoxia (meconium staining in the skin, signs of cyanosis), predisposition to farrowing difficulties (stillborn with big head, umbilical cord content and length) and risk of asphyxia (respiratory difficulties, umbilical cord node, membrane wrapping in bornalive piglets). Sow and piglet behaviour was recorded during farrowing using 24 time lapse video (VHS Panasonic

Table 1 Criteria for piglet birth difficulties and risk of hypoxia

\begin{tabular}{|c|c|}
\hline Criterion & Definition \\
\hline \multicolumn{2}{|l|}{ Birth difficulties } \\
\hline Big head & $\begin{array}{l}\text { The head is bigger than normal, in } \\
\text { proportion to the rest of the body and } \\
\text { seems to be directly associated to it, } \\
\text { without sliming down at the neck. }\end{array}$ \\
\hline Birth orientation & $\begin{array}{l}\text { Whether the piglet is born with head } \\
\text { first or hind legs or back first. }\end{array}$ \\
\hline Membrane attachment & $\begin{array}{l}\text { The piglet is partially shut in its } \\
\text { placenta (without difficulty to breath) } \\
\text { or the membrane remains stuck on the } \\
\text { umbilical cord. }\end{array}$ \\
\hline Membrane wrapping & $\begin{array}{l}\text { The piglet is totally shut in the } \\
\text { membrane that prevents it from } \\
\text { breathing. }\end{array}$ \\
\hline Membrane obstruction & $\begin{array}{l}\text { Membrane wrapping or membrane } \\
\text { attachment. }\end{array}$ \\
\hline Umbilical cord length & $\begin{array}{l}\text { Length is assumed to be proportional } \\
\text { to the distance between the position } \\
\text { in the uterine horn and the cervix. }\end{array}$ \\
\hline
\end{tabular}

\begin{tabular}{ll}
$\begin{array}{l}\text { Risk of hypoxia } \\
\text { Cyanosis under the body }\end{array}$ & $\begin{array}{l}\text { Cyanosis colour, sign of blood } \\
\text { concentration in the region of vital } \\
\text { organs. } \\
\text { Cyanosis colour on the head may be a } \\
\text { sign of blood concentration in the } \\
\text { brain. }\end{array}$ \\
Umbilical cord node & $\begin{array}{l}\text { Presence of a node on the umbilical } \\
\text { cord. Node prevents normal blood } \\
\text { flow and hence, normal gas exchange } \\
\text { between the sow and its progeny. } \\
\text { Either there is blood in it, either it is } \\
\text { empty. An empty cord may be the sign } \\
\text { of a premature rupture of the cord. }\end{array}$ \\
\hline \hline
\end{tabular}

video recorder associated with DPX9 multiplexer advanced technology video). The video allowed the birth time of each piglet to be recorded, and more precise and missing values from the direct observations to be retrieved. The birth orientation of each piglet and time to first placenta expulsion were also obtained by video observations.

\section{Statistical analyses}

A large number of traits potentially involved in stillbirth and differences between the two genetic groups were recorded. Traits describing sow condition at farrowing included age at insemination (Al), gestation length (GEST), sow weight (SWF) and fatness (FAT = mean of six measurements on each side of the spine at the levels of hip joint, last rib and shoulder) at farrowing. Prolificacy traits included the numbers of prenatal deaths (PRE $=$ mummified + macerated piglets), stillborn (NSB) and born-alive piglets (NBA). The number born in total $(\mathrm{NBT}=\mathrm{NSB}+\mathrm{NBA})$, the number born in global (NBG $=\mathrm{NBT}+\mathrm{PRE})$ and the proportion of stillborn piglets per litter $(P S B=N S B / N B T)$ were derived from the previous variables. The piglet individual birth weight (BW) allowed litter birth weight (LBW) as well as the coefficient of variation (CVBW), standard deviation (STDBW), maximum (MAXBW) and minimum (MINBW) of within-litter individual piglet birth weights to be calculated. Similarly, birth interval, defined as the period of time between two successive births, allowed several kinetics traits to be computed:

- the farrowing duration (FD), defined as the interval of time between the birth of the first piglet and that of the last piglet of a litter;

- the time elapsed from the onset of farrowing to piglet birth (ELAPS); farrowings ending more than $10 \mathrm{~h}$ after the birth of the first piglet were considered as abnormal and discarded;

- the average (BI), maximum (MAXBI) and standard deviation (SDBI) of birth intervals, as well as the interval before a stillborn piglet birth (IBSB);

- the time of first placenta expulsion (PLA), defined as the time interval between the last piglet born and the first placenta expulsion.

Traits associated with farrowing difficulties were those described in Table 1; they were considered as count data, except umbilical cord length, which was treated as a continuous trait.

Sow traits (including litter size, litter weight and kinetics traits), as well as piglet birth weight and umbilical cord length, were analysed with a mixed linear model including the fixed effects of genetic group (GG: G77 or G98), parity (first or second), a random batch effect plus an additional random effect of the sow, using the MIXED procedure of SAS software (Statistical Analysis Systems Institute, 2001). When the interaction between parity and GG was significant, estimates were obtained for each parity. Leastsquares means were estimated with and without adjustment for litter size. The age and weight at measurement 
were included as additional covariates for the analysis of SWF and FAT, respectively. The analyses of FD, BI and SDBI were performed in the same way but after a Box-Cox transformation in order to normalise their distribution.

Piglets' probability of stillbirth (SB) and traits associated with farrowing difficulties other than umbilical cord length were analysed using a generalised estimating equation approach applied to a generalised linear mixed model, with the GENMOD procedure of SAS (2001). The model assumed a binomial distribution of the dependent variable and a logit link function, and included the fixed effects of genetic group and dam parity, as well as a random birth litter effect with an exchangeable correlation matrix.

To obtain a better understanding of the relationship of stillbirth risk with the progress of farrowing, additional analyses of piglet's probability of stillbirth were performed with parity, FD, GG, time of farrowing when birth occurred, recorded as first, second and third part of farrowing, as fixed effects and the litter of birth as a random effect, using the GENMOD procedure of SAS (2001). The three parts of farrowing were established after a first division of the whole farrowing period in 10 equal periods of time ( $P 1$ to P10) followed by a grouping of P1 and P2 (first part), P3 to P8 (second part) and P9 and P10 (third part) so as to have a similar number of piglets in each part. Two further sets of factors were considered in two successive analyses by including them as additional independent variables in the model previously described for $S B$, without the time of farrowing effect. The first set included litter size (NBT, PRE) and piglet weight (BW, CVBW) traits. The second set was performed on a subset of data and included additional traits related to farrowing kinetics (ELAPS, SDBI, PLA) and sow farrowing condition (FAT, SWF) traits. In each of these additional analyses, the contribution of each effect to the variance reduction was evaluated adding them one by one and quantified with the coefficient of determination of Hosmer and Lemeshow (1989).

The realised genetic trends from 1977 to $1998(\Delta G)$ and their standard errors (s.e. $\Delta G$ ) were estimated for each considered trait as proposed by Smith (1977): $\Delta G=2 \times$ (G98 mean-G77 mean) and s.e. $\Delta G=2 \times$ s.e. (G98 mean-G77 mean). A total of 137 litters and 1679 piglets were analysed; their distribution according to genetic group and parity are shown in Table 2 . All estimates are given on the inverse transformed scale.

\section{Results}

\section{Genetic trends for litter size, litter weight and farrowing kinetics traits}

Genetic group least-squares means and estimated genetic trends for litter traits, including prolificacy and farrowing mortality, are shown in Table 3. Due to limitations in the experimental facilities, sows were rather old at the first insemination. The higher age at insemination of G98 was due to a random choice of older gilts and did not reflect any
Table 2 Number of records according to dam parity and genetic group

\begin{tabular}{lcccc}
\hline \hline Parity & Genetic group & Dams & Boars & Piglets \\
\hline 1 & G77 & 38 & 10 & 449 \\
& G98 & 40 & 10 & 478 \\
2 & G77 & 30 & 11 & 363 \\
& G98 & 29 & 5 & 389 \\
\hline \hline
\end{tabular}

difference in sexual maturity. G77 sows had a longer gestation length than G98 sows, and a tendency $(P=0.08)$ remained when adjusting for litter size. The contrasts between genetic groups for litter size widely differed between the first and second parity. Almost no difference was observed in first-parity litters, whereas second-parity mean litter size of $\mathrm{G} 98$ exceeded that of $\mathrm{G} 77$ by 2.3 piglets. Yet, both first- and second-parity G98 litters had a higher number and proportion of stillbirths than G77 litters, resulting in a four times greater probability of stillbirth in G98 as compared with G77 piglets.

Average piglet weights and corresponding genetic trends are presented in Table 4. G98 piglets were heavier at birth than G77 piglets. As a consequence, litter birth weight increased by more than $5 \mathrm{~kg}$ over the 1977-98 period of time. Within-litter BW dispersion traits (MINBW, MAXBW, STDBW and (VBW) did not exhibit any significant genetic trend.

Farrowing duration and birth intervals did not differ between the two genetic groups, neither traits describing birth irregularity (SDBI, MAXBI and IBSB, results not shown). IBSB was on average 13 min longer than BI. PLA was similar in both groups and showed a large variability.

\section{Genetic trends in birth difficulties and risk of hypoxia and asphyxia}

Estimates associated with stillborn characteristics, risk of hypoxia and asphyxia are shown in Table 5 . Birth difficulties were not associated with membrane wrapping, although G98 piglets had a 1.9-times higher risk of getting born in their membrane than $\mathrm{G} 77$ piglets. Though very rare (only 10 cases), the risk of having an umbilical node was higher in G98 piglets. The examination of stillborn piglets showed that stillborn G98 piglets tended to suffer more from cyanosis and had longer umbilical cords that were more frequently empty (nearly three-times lower probability of blood presence inside the cord).

Results from modelling probability of stillbirth (Table 6) highlighted between genetic group differences in the main factors of variation of stillbirth, albeit the reduction in the residual sum of squares due to the successive addition of each explanatory variable demonstrated that time of birth was the major determinant of stillbirth in both genetic groups $(21.98 \%$ and $22.27 \%$ variance reduction in $\mathrm{G} 77$ and G98, respectively). Gestation length, the presence of prenatal dead piglets and the variability in within-litter birth 
Table 3 Comparison of sow characteristics at farrowing in two populations produced by use of frozen semen collected on boars born in 1977 or 1998 (G77 and G98): least-squares means, estimated genetic trends ( $\Delta \mathrm{G})$ and standard errors (s.e. $\Delta \mathrm{G})^{\dagger}$

\begin{tabular}{|c|c|c|c|c|c|c|c|}
\hline Traits $^{\ddagger}$ & Parity & $n \mathrm{G} 77$ & $n$ G98 & G77 mean & G98 mean & $\Delta G$ (s.e. $\Delta G$ ) & $P>|t| \mathrm{H} 0: \Delta G=0$ \\
\hline \multicolumn{8}{|l|}{ Gestation } \\
\hline \multirow[t]{2}{*}{ Al (days) } & 1 & 38 & 40 & 400.5 & 417.7 & $+34.4(13.6)$ & \multirow[t]{2}{*}{ ** } \\
\hline & 2 & 30 & 29 & 527.3 & 539.0 & $+23.4(15.2)$ & \\
\hline GEST (days) & $1+2$ & 68 & 69 & 113.6 & 112.9 & $-1.4(0.6)$ & \multirow[t]{2}{*}{ * } \\
\hline AGEST (days) & $1+2$ & 68 & 69 & 113.5 & 113.0 & $-1.0(0.6)$ & \\
\hline \multirow[t]{2}{*}{ FAT $(\mathrm{mm})$} & 1 & 35 & 36 & 28.0 & 24.5 & $-7.0(1.8)$ & \multirow{4}{*}{$\begin{array}{c}* * * \\
* *\end{array}$} \\
\hline & 2 & 21 & 19 & 26.9 & 22.5 & $-8.8(3.5)$ & \\
\hline \multirow[t]{2}{*}{ SWF (kg) } & 1 & 38 & 37 & 261.8 & 266.9 & $+10.2(7.4)$ & \\
\hline & 2 & 23 & 25 & 286.3 & 292.9 & +13.2 (13.8) & \\
\hline \multicolumn{8}{|l|}{ Litter size traits } \\
\hline \multirow[t]{2}{*}{ NBG $(n)$} & 1 & 30 & 28 & 12.2 & 12.4 & $+0.4(2.2)$ & \multirow{6}{*}{ * } \\
\hline & 2 & 27 & 25 & 12.3 & 14.6 & $+4.6(2.1)$ & \\
\hline \multirow[t]{2}{*}{$\mathrm{NBT}(n)$} & 1 & 38 & 40 & 11.8 & 12.1 & $+0.6(1.8)$ & \\
\hline & 2 & 30 & 29 & 12.1 & 13.4 & $+2.6(1.9)$ & \\
\hline \multirow[t]{2}{*}{ Sex ratio } & 1 & 38 & 40 & 0.51 & 0.54 & $+0.04(0.06)$ & \\
\hline & 2 & 30 & 29 & 0.58 & 0.52 & $-0.12(0.06)$ & \\
\hline \multicolumn{8}{|l|}{ Mortality traits } \\
\hline NSB $(n)$ & $1+2$ & 68 & 69 & 0.81 & 1.48 & $+1.34(0.60)$ & * \\
\hline PPRE (\%) & $1+2$ & 67 & 63 & 2.5 & 3.9 & $+2.8(2.2)$ & \\
\hline PSB (\%) & $1+2$ & 68 & 69 & 6.2 & 10.4 & $+8.4(4.0)$ & * \\
\hline Probability of stillbirth & $1+2$ & 812 & 867 & 0.054 & 0.102 & +0.096 & ** \\
\hline
\end{tabular}

${ }^{\dagger} \Delta G=2 \times(G 98$ mean-G77 mean) and s.e. $\Delta G=2 \times$ s.e. (G98 mean-G77 mean).

${ }^{\ddagger} \mathrm{AI}=$ age at insemination; GEST = gestation length; AGEST = gestation length adjusted for NBT; FAT = sow fatness at farrowing; SWF = sow weight at farrowing; $N B G=$ number born in global; $N B T=$ number born in total; sex ratio = proportion of males in the litter; PRE = number of prenatal deaths; PPRE $=$ proportion of prenatal deaths; NSB $=$ number of stillbirths. PSB $=$ proportion of stillbirths.

Table 4 Comparison of litter and piglet weight characteristics at farrowing between two populations produced by use of frozen semen collected on boars born in 1977 or 1998 (G77 and G98): least-squares means, estimated genetic trends ( $\Delta \mathrm{G}$ ) and standard errors (s.e. $\Delta \mathrm{G})^{+}$

\begin{tabular}{|c|c|c|c|c|c|c|}
\hline Traits $^{\ddagger}$ & $n$ G77 & $n \mathrm{G} 98$ & G77 mean & G98 mean & $\Delta G($ s.e. $\Delta G)$ & $\operatorname{Pr}>|t| \mathrm{HO}: \Delta G=0$ \\
\hline \multicolumn{7}{|c|}{ Piglet and litter weight traits } \\
\hline BW (kg) & 632 & 607 & 1.30 & 1.37 & $+0.15(0.10)$ & \\
\hline$A B W(k g)$ & 632 & 607 & 1.24 & 1.37 & $+0.26(0.08)$ & ** \\
\hline LBW $(\mathrm{kg})$ & 56 & 49 & 14.25 & 16.81 & $+5.12(2.14)$ & * \\
\hline MINBW $(\mathrm{kg})$ & 56 & 49 & 0.91 & 0.97 & $+0.12(0.12)$ & \\
\hline AMINBW (kg) & 56 & 49 & 0.88 & 1.01 & $+0.26(0.10)$ & ** \\
\hline MAXBW $(\mathrm{kg})$ & 56 & 49 & 1.66 & 1.75 & $+0.18(0.14)$ & \\
\hline AMAXBW $(\mathrm{kg})$ & 56 & 49 & 1.65 & 1.76 & $+0.22(0.14)$ & \\
\hline CVBW $(\mathrm{kg})$ & 52 & 48 & 20.20 & 18.88 & $-2.64(3.50)$ & \\
\hline ACVBW $(\mathrm{kg})$ & 52 & 48 & 20.66 & 18.44 & $-4.44(3.06)$ & \\
\hline STDBW $(\mathrm{kg})$ & 55 & 50 & 0.24 & 0.24 & $-0.00(0.04)$ & \\
\hline ASTDBW $(\mathrm{kg})$ & 55 & 50 & 0.24 & 0.23 & $-0.02(0.04)$ & \\
\hline \multicolumn{7}{|c|}{ Born-alive piglet weight } \\
\hline $\mathrm{BW}(\mathrm{kg})$ & 578 & 534 & 1.30 & 1.38 & $+0.16(0.10)$ & \\
\hline$A B W(k g)$ & 578 & 534 & 1.25 & 1.38 & $+0.26(0.08)$ & ** \\
\hline \multicolumn{7}{|c|}{ Stillborn piglet weight } \\
\hline BW (kg) & 54 & 73 & 1.20 & 1.28 & $+0.16(0.10)$ & \\
\hline$A B W(k g)$ & 54 & 73 & 1.17 & 1.28 & $+0.22(0.18)$ & \\
\hline
\end{tabular}

${ }^{\dagger} \Delta G=2 \times$ (G98 mean-G77 mean) and s.e. $\Delta G=2 \times$ s.e. (G98 mean-G77 mean).

${ }^{\ddagger} \mathrm{BW}=$ birth weight; $\mathrm{ABW}=$ birth weight adjusted for NBT; LBW = litter birth weight; MINBW = minimum within-litter birth weight; AMINBW = minimum within-litter birth weight adjusted for NBT; MAXBW = maximum within-litter birth weight; AMAXBW = maximum within-litter birth weight adjusted for NBT; CVBW = coefficient of variation of within-litter piglet weight; ACVBW = coefficient of variation of within-litter piglet weight adjusted for NBT; SDBW = standard deviation of within-litter piglet weight; ASDBW = standard deviation of within-litter piglet weight adjusted for NBT. 
Canario, Rydhmer, Gogué, Tribout and Bidanel

Table 5 Comparison of total litter, stillborn and born-alive piglet characteristics at birth between two populations of sows produced by use of frozen semen collected on boars born in 1977 or 1998 (G77 and G98 sows): occurrence and probability of observation (P)

\begin{tabular}{|c|c|c|c|c|c|}
\hline & Occurrence/n G77 & Occurrence/n G98 & G77 P & G98 P & $\operatorname{Pr}>|t| \mathrm{H} 0: \Delta G=0$ \\
\hline \multicolumn{6}{|l|}{ Born piglets' difficulties } \\
\hline Membrane wrapping & $9 / 605$ & $14 / 632$ & 0.014 & 0.020 & \\
\hline Membrane attachment & $12 / 459$ & $16 / 549$ & 0.025 & 0.028 & \\
\hline Membrane obstruction & $19 / 459$ & $28 / 549$ & 0.040 & 0.048 & \\
\hline Umbilical cord node & $1 / 604$ & $9 / 667$ & 0.002 & 0.013 & * \\
\hline \multicolumn{6}{|l|}{ Stillborn piglets' characteristics } \\
\hline Cyanosis under the body & $16 / 37$ & $31 / 60$ & 0.401 & 0.562 & * \\
\hline Head oedema & $14 / 39$ & $28 / 68$ & 0.237 & 0.275 & \\
\hline Big head & $6 / 16$ & $12 / 39$ & 0.239 & 0.231 & \\
\hline Umbilical cord contains blood $^{\dagger}$ & $23 / 38$ & $26 / 69$ & 0.603 & 0.380 & * \\
\hline Umbilical cord length (cm) & 41 & 73 & 25.5 & 34.1 & * \\
\hline \multicolumn{6}{|l|}{ Born-alive piglets' difficulties } \\
\hline Umbilical cord node & $1 / 571$ & $6 / 590$ & 0.002 & 0.009 & \\
\hline Birth orientation ${ }^{\ddagger}$ & $80 / 278$ & $90 / 273$ & 0.233 & 0.252 & \\
\hline Membrane wrapping & $6 / 580$ & $5 / 554$ & 0.010 & 0.009 & \\
\hline Membrane attachment & $6 / 435$ & $10 / 492$ & 0.013 & 0.020 & \\
\hline Membrane obstruction & $10 / 435$ & $15 / 492$ & 0.022 & 0.030 & \\
\hline
\end{tabular}

${ }^{+} 0=$ empty, 1 = full.

${ }^{\ddagger} 0=$ head first, $1=$ hind legs or back first.

Table 6 Reduction (R) of deviance (D) for probability of piglet stillbirth due to the addition of several potentially explanatory factors either globally or for two populations produced by use of frozen semen collected on boars born in 1977 or 1998 (G77 and G98)

\begin{tabular}{|c|c|c|c|c|c|c|c|c|c|}
\hline \multirow[b]{2}{*}{ Model $^{\dagger}$} & \multicolumn{3}{|c|}{ Global } & \multicolumn{3}{|c|}{ G77 } & \multicolumn{3}{|c|}{ G98 } \\
\hline & $\operatorname{Sign}^{\ddagger}$ & $D$ & $R(\%)$ & Sign & $D$ & $R(\%)$ & Sign & $D$ & $R(\%)$ \\
\hline $0:$ intercept & & 488.76 & & & 288.53 & - & & 198.05 & - \\
\hline $1: 0+P$ & - & 488.32 & 0.09 & - & 287.85 & 0.24 & + & 198.04 & 0.01 \\
\hline $2: 1+$ SEX & - & 488.02 & 0.06 & - & 287.77 & 0.03 & - & 197.67 & 0.19 \\
\hline $3: 2+$ GEST & - & 477.93 & 2.07 & - & 269.89 & 6.21 & - & 197.58 & 0.05 \\
\hline \multicolumn{10}{|l|}{ Litter size } \\
\hline $4: 3+N B T$ & - & 470.78 & 1.50 & - & 265.25 & 1.72 & - & 192.75 & 2.44 \\
\hline $5: 4+\mathrm{NBT}^{2}$ & + & 470.45 & 0.07 & + & 265.25 & 0.00 & + & 192.45 & 0.16 \\
\hline $6: 5+P R E$ & + & 465.54 & 1.04 & + & 248.06 & 6.48 & - & 192.44 & 0.01 \\
\hline \multicolumn{10}{|l|}{ Piglet weight } \\
\hline $7: 6+B W$ & - & 462.57 & 0.64 & - & 247.96 & 0.04 & - & 191.97 & 0.24 \\
\hline $8: 7+B W^{2}$ & + & 460.09 & 0.54 & + & 243.29 & 1.88 & + & 189.34 & 1.37 \\
\hline $9: 8+C V B W$ & + & 453.54 & 1.42 & + & 232.25 & 4.54 & + & 188.89 & 0.24 \\
\hline \multicolumn{10}{|l|}{ Farrowing kinetics } \\
\hline $10: 9+$ ELAPS & + & 361.62 & 20.27 & + & 181.21 & 21.98 & + & 146.78 & 22.29 \\
\hline $11: 10+$ SDBI & + & 360.60 & 0.28 & - & 179.31 & 1.05 & + & 145.72 & 0.72 \\
\hline $12: 11+$ PLA & - & 360.60 & 0.00 & - & 177.62 & 0.94 & + & 140.35 & 3.69 \\
\hline \multicolumn{10}{|c|}{ Sow body condition } \\
\hline $13: 12+$ FAT & + & 359.35 & 0.35 & + & 175.75 & 1.05 & - & 111.89 & 20.28 \\
\hline $14: 13+$ SWF & - & 348.76 & 2.95 & - & 173.15 & 1.48 & + & 111.46 & 0.38 \\
\hline
\end{tabular}

${ }^{\dagger} \mathrm{P}=$ sow parity. SEX $=$ sex of the piglet. GEST = gestation length. NBT = number born in total. PRE = number of prenatal deaths. BW = individual birth weight. CVBW $=$ coefficient of variation of within-litter individual birth weight. ELAPS = time of birth, measured as time elapsed from the onset of farrowing. $\mathrm{SDBI}=$ standard deviation of within-litter birth interval between successive births. PLA $=$ time of first placenta expulsion. FAT = sow fatness at farrowing. SWF $=$ sow weight at farrowing.

₹Sign of the corresponding estimate indicates whether the association between probability of stillbirth and the explicative variable is negative or positive. 


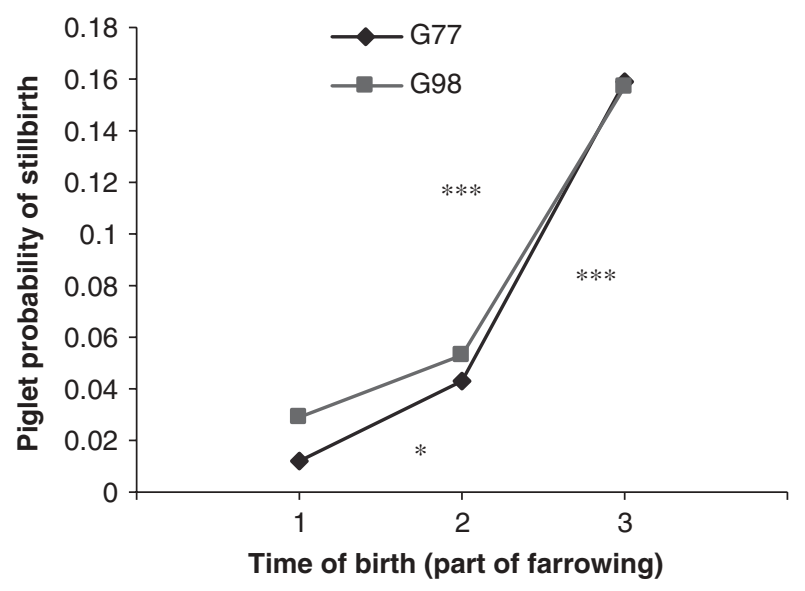

Figure 1 Effect of time of birth (first, second or third part of farrowing) on piglet's probability of stillbirth in two populations produced by use of frozen semen collected on boars born in 1977 or 1998 (G77 and G98 piglets).

weight were strongly involved in stillbirth of G77 piglets, whereas sow body condition and, to a much lesser extent, the time of first placenta expulsion as well as the square component of piglet birth weight (i.e. the influence of the lightest and biggest piglets within the litter) resulted in strong deviance reductions in G98 litters. As a result of these differences, only two factors of variation of stillbirth reached significance in the joint analysis of G77 and G98 data: FAT, which was negatively associated with stillbirth and ELAPS, which was positively associated with stillbirth. In both genetic groups, a highly significant increase in piglet's probability of stillbirth occurred as farrowing proceeded (Figure 1).

\section{Discussion}

This is to our knowledge the first time that genetic trends for a large number of maternal ability traits were estimated in pigs. Although the accuracy of the results is limited by the size of the experiment, much original information is provided regarding the effects of selection and the relative importance of the different components of maternal ability for piglet survival. This information will be of great interest to define more adequate breeding goals and contribute to implementing biologically more sustainable breeding plans.

Prolificacy results showed strong discrepancies between the first and the second parity. Although the random nature of this difference cannot be totally excluded due to the rather limited amount of data available, it may partly be related to the use of frozen semen in the first parity, which could have prevented the genetic differences in prolificacy detected in the previous generation (Tribout et al., 2003) to be expressed. Another potential explanation might be a lower response to selection in the first parity. Indeed, a lower response to selection in the first parity was also obtained in the previous generation (Canario et al., 2006c).
Although number born in total did not significantly differ between G77 and G98 litters, presumably because of the limited number of litters produced, the genetic trend in the second parity was in agreement with the results of Tribout et al. (2003). Moreover, the number of piglets born in global (NBG) differed between G77 and G98 litters, as a consequence of a higher number of both NBT and prenatal deaths in G98 litters. These higher prenatal losses could be due to an increased competition between foetuses in late gestation in relationship with intrauterine crowding, which may result in an insufficient development of some placentas (English and Morrison, 1984; Van der Lende et al., 2000). Indeed, attempts to phenotypically increase the number of embryos in the uterus (e.g. Vallet, 2000) resulted in higher losses in late gestation. Conversely, Johnson et al. (1999) did not obtain any deterioration of late foetal survival in a line selected for increased litter size. Intrauterine crowding may be accentuated by the higher growth potential of G98 foetuses (Canario et al., 2007).

The deterioration of piglet survival was larger than that found by Tribout et al. (2003). A similar degradation of piglet survival was observed over the last years in French pig herds (see the large-scale study of Le Cozler et al. (2002)) and in several other experimental studies (review of Blasco et al., 1995; Johnson et al., 1999). This unfavourable trend is generally considered as a response to selection for the number born in total. It is not only due to a scale effect, as G98 first-parity piglets had a higher probability of stillbirth than G77 piglets, albeit litter size was similar in both groups. Johnson et al. (1999) suggested that it might be mediated through a negative effect on birth weight. Lighter piglets would be less developed at birth, in association with problems in tissue differentiation and growth (Klemcke et al., 1993) and would have a higher probability of stillbirth. In the current study, stillborn piglets had a $100 \mathrm{~g}$ lower weight than piglets born alive, which is in accordance with other recent studies (Leenhouwers et al., 1999 and 2003; Knol et al., 2002a). This weight difference has remained stable between 1977 and 1998. Yet, things are somewhat more complex in the present study, as piglet birth weight has increased over the last 20 years, presumably as a consequence of selection for post-weaning growth rate. This increase is in agreement with findings from Tribout et al. (2003), even if somewhat higher values were obtained here: $+240 \mathrm{~g} \mathrm{v} .+180 \mathrm{~g}$ for BW adjusted for litter size. Moreover, unlike many other studies (e.g. Leenhouwers et al., 1999 and 2003; Knol et al., 2002b; Canario et al., 2006a), individual birth weight did not appear as a major determinant of probability of stillbirth in G77 and G98 litters. This discrepancy may be partly related to the way stillborn piglets were defined. Unlike most other studies, where piglets born alive which die shortly after birth are classified as stillborn piglets, the current study only included piglets born dead. Birth weight becomes a major factor for survival in early lactation (Mesa et al., 2006). Our result was in agreement with Leenhouwers et al. (2001), who found independence between farrowing survival and birth 
weight in a study where farrowing was carefully supervised. The only noticeable influence of birth weight concerns the quadratic component of birth weight in G98 sows, which is positively associated with stillbirth. This means that modern piglets with extreme weights tend to have a higher probability of stillbirth. On the one hand, heavy piglets would suffer from difficulties to go through the birth canal, especially in first-parity sows (Pejsak, 1984). On the other hand, England (1974) suggested that smaller piglets would be propelled less efficiently and remain in the uterine horn longer, overtaken by bigger ones. Thus, they would suffer more from hypoxia. Within-litter variation of birth weight was important for piglet survival in $\mathrm{G} 77$ litters. This positive effect of BW homogeneity is in agreement with the results of Tribout et al. (2003).

Farrowing duration is known to be a key determinant of intra-partum stillbirth (e.g. Fahmy and Flipot, 1981; Canario et al., 2006a). It did not significantly differ between the two genetic groups of sows, even if G98 second-parity farrowings were slightly longer than the G77 ones. However, the time elapsed from the onset of farrowing appeared as the most important contributor to probability of stillbirth in both G77 and G98 litters. The last piglets born in a litter are more likely to suffer from a larger number of uterine contractions, to have a higher risk of premature rupture of the umbilical cord, leading to a higher risk of hypoxia and stillbirth (Randall, 1972a and 1972b). These time effects were similar in both genetic groups, but the longer umbilical cord of G98 stillborn piglets may have increased the risk of nodes as compared with G77 piglets. The larger occurrence of cyanosis under the body in G98 stillborn piglets is an additional sign of severe hypoxia. Cyanosis is likely due to a concentration of blood around vital organs, particularly the heart, after the rupture of the umbilical cord (AlonsoSpilsbury et al., 2005). In this study, the higher proportion of empty cords in stillborn G98 piglets is another cue for a premature rupture of the umbilical cord. This rupture lowers placenta blood pressure, causes a partial collapse of the chorionic villi and thus facilitates placenta detachment (Perry, 1954). No differences in time to first placenta expulsion were observed between the two genetic groups, but this simple measurement might not be the best one to reveal differences in premature rupture of the umbilical cord and early decomposition of the farrowing placental tract. No trend in membrane obstruction was found. However, Biensen et al. (1999) proposed with reference to the Meishan breed that an intense selection for litter size might result in an indirect selection for small, thin but highly vascular placentas. A general thinning of foetal membranes and cords with higher risk of placenta detachment could be involved in the larger stillbirth rate observed in G98 sows.

Sow body fat condition at farrowing strongly influenced probability of stillbirth in G98 litters, in agreement with the results of Herpin et al. (1993). Selection for litter size has increased the resource demanding processes of pregnancy and lactation, whereas selection for fast lean growth may have indirectly put an increased demand on delivery of nutrients by the placenta and may have put conceptuses at a greater risk of prenatal mortality (Vallet et al., 2002) and stillbirth (Grandinson et al., 2005). Selection for increased lean growth has resulted in higher prenatal mortality in several experiments (Vangen, 1972; Kerr and Cameron, 1995). Since animals from both genetic groups were fed the same diet according to the same norm during gestation, G98 sows may have been restricted in their ability to provide enough nutrients to their foetuses in late gestation.

Gestation length decreased by more than 1 day, probably in relationship with the increase in prolificacy. Contrary to previous studies suggesting that despite its low variability, gestation length may be an additional factor involved in piglet maturation at birth and birth survival (Hanenberg et al., 2001; Rydhmer and Lundeheim, 2005; Canario et al., 2006a), its importance for piglet survival was found in G77 piglets only.

Additional parameters have been tested as potential components of the observed difference in probability of stillbirth. Results from studies investigating the influence of birth orientation on stillbirth probability are controversial (Hughes and Varley, 1980). It does not seem to be involved in the larger number of G98 stillbirths, as no significant genetic trend in birth orientation was observed. Likewise, no significant differences in membrane wrapping or attachment or in the proportion of piglets with big heads were detected. The observed trend on the sex ratio in second parity might be important; but as male piglets show a higher probability of stillbirth than females (Canario et al., 2006a), it would rather reduce the difference between G77 and G98 genetic groups. Pedersen et al. (2006) reported a more variable farrowing process, i.e. a larger standard deviation in birth interval in litters with stillbirths and a decelerating rhythm of expulsion with progress of farrowing, which may result in a higher risk of hypoxia. No significant trends were observed for these traits in the current study.

\section{Conclusions and implications}

The selection of French LW pigs has until recently considerably increased the risk of stillbirth. Previous results have shown that the use of a proper selection criterion such as the number born alive (Johnson et al., 1999; Canario et al., 2006b) or the maternal component of probability of stillbirth (Leenhouwers et al., 2003) instead of total number born, should prevent further degradation of farrowing mortality. Our results give some insight into the mechanisms associated with this increased mortality and into the traits that may be important to consider when defining future breeding goals. In particular, they confirm that increasing birth weight is unlikely to be a good way to decrease stillbirth probability and suggest that sow body condition at farrowing can be involved in farrowing survival, which is of particular interest, as it is also likely to influence piglet survival during lactation (Grandinson et al., 2005). Yet, additional studies remain necessary to 
understand better the complex mechanisms involved in piglet survival at farrowing and during lactation in order to be able to predict better and control the long-term effects of selection. The use of high-throughput genomic technologies is likely to be of high interest for such investigations.

\section{Acknowledgements}

The contributions of students (A. Jamois, A. Bonaventure, M. Quiertant and E. Mosnier) who participated to the data collection, helping to keep the first author awake during the long nights on the farm, and those who were involved in preliminary analyses are gratefully acknowledged. We also thank the staff of Bourges experimental unit for its participation in the data collection. This work was supported by the INRA and the French Technical Institute in Pig Production (IFIP).

\section{References}

Alonso-Spilsbury M, Mota-Rojas D, Villanueva-García D, Martínez-Burnes J, Orozco H, Ramírez-Necoechea R, Mayagoitia AL and Trujillo ME 2005. Perinatal asphyxia pathophysiology in pig and human: a review. Animal Reproduction Science 90, 1-30.

Bidanel JP, Canario L, Rosendo-Poncé A and Tribout T. 2005. Conséquences de la sélection pour la prolificité des truies. Journées GTV Nantes, pp. 635-642.

Biensen NJ, Wilson ME and Ford SP 1999. The impacts of uterine environment and fetal genotype on conceptus size and placental vascularity during late gestation in pigs. Journal of Animal Science 77, 954-959.

Blasco A, Bidanel JP and Haley CS 1995. Genetics and neonatal survival. In The neonatal pig: development and survival (ed. MA Varley), pp. 17-38. CAB International, Wallingford, UK.

Canario L, Cantoni E, Le Bihan E, Caritez JC, Billon Y, Bidanel JP and Foulley JL 2006a. Between breed variability of stillbirth and its relationship with sow and piglet characteristics. Journal of Animal Science 84, 3185-3196.

Canario L, Roy N, Gruand J and Bidanel JP 2006b. Genetic variation of farrowing kinetics traits and relationships with litter size and perinatal mortality in French Large White sows. Journal of Animal Science 84, 1053-1058.

Canario L, Tribout T and Bidanel JP 2006c. Genetic trends for reproduction and maternal abilities in French Large White pigs. Proceedings of the 57th annual meeting of the European Association for Animal Production, Antalya, Turkey, G10.1.

Christianson WT 1992. Stillbirths, mummies, abortions and early embryonic death. In Veterinary clinics of North America: food animal practice. Swine reproduction (ed. RC Tubbs and AD Leman), vol. 8, no. 3, pp. 623-639. Saunders, Philadelphia, PA.

England DC 1974. Husbandry components in prenatal and perinatal development in swine. Journal of Animal Science 38, 1045-1049.

English PR and Morrison V 1984. Causes and prevention of piglet mortality. Pig News Information 5, 369-376.

Fahmy MH and Flipot P 1981. Duration of farrowing and birth and nursing order in relation to piglet growth and survival. World Review of Animal Production 18, 17-24.

Fraser D, Phillips PA and Thompson BK 1997. Farrowing behaviour and stillbirth in two environments: an evaluation of the restraint stillbirth hypothesis. Applied Animal Behaviour Science 55, 51-66.

Grandinson K, Rydhmer K, Strandberg E and Solanes FX 2005. Genetic analysis of body condition in the sow during lactation, and its relation to piglet survival and growth. Animal Science 80, 33-40.

Hanenberg EHAT, Knol EF and Merks JWM 2001. Estimates of genetic parameters for reproduction traits at different parities in Dutch Landrace pigs. Livestock Production Science 69, 179-186.
Herpin P, Le Dividich J and Amaral N 1993. Effect of selection for lean tissue growth on body composition and physiological state of the pig at birth. Journal of Animal Science 71, 2645-2653.

Herpin P, Le Dividich J, Hulin JC, Fillaut M, De Marco F and Bertin R 1996. Effects of level of asphyxia during delivery on viability at birth and early postnatal viability of newborn piglets. Journal of Animal Science 74, 2067-2075.

Hosmer DW and Lemeshow S 1989. Applied logistic regression. Wiley, New York, NY.

Hughes PE and Varley MA 1980. Reproduction in the pig. Butterworth, London. Johnson RK, Nielsen MK and Casey DS 1999. Responses in ovulation rate, embryonal survival, and litter traits in swine to 14 generations of selection to increase litter size. Journal of Animal Science 77, 541-557.

Kerr JC and Cameron ND 1995. Reproductive performance of pigs selected for components of efficient lean growth. Animal Science 60, 281-290.

Klemcke HG, Lunstra DD, Brown-Borg HM, Borg KE and Christenson RK 1993. Association between low birth weight and increased adrenocortical function in neonatal pigs. Journal of Animal Science 71, 1010-1018.

Knol EF, Ducro BJ, Van Arendonk JAM and Van der Lende T 2002a. Direct, maternal and nurse sow genetic effects on farrowing-, pre-weaning- and total piglet survival. Livestock Production Science 73, 153-164.

Knol EF, Leenhouwers Jl and VanderLende T 2002b. Genetic aspects of piglet survival. Livestock Production Science 78, 47-55.

Le Cozler Y, Guyomarc'h C, Pichodo X, Quinio PY and Pellois H 2002. Factors associated with stillborn and mummified piglets in high-prolific sows. Animal Research 51, 261-268.

Leenhouwers Jl, Van der Lende T and Knol EF 1999. Analysis of stillbirth in different lines of pig. Livestock Production Science 57, 243-253.

Leenhouwers JI, De Almeida Junior CA, Knol EF and Van der Lende T 2001. Progress of farrowing and early postnatal pig behavior in relation to genetic merit for pig survival. Journal of Animal Science 79, 1416-1422.

Leenhouwers Jl, Wissink P, Van der Lende T, Paridaans H and Knol EF 2003. Stillbirth in the pig in relation to genetic merit for farrowing survival. Journal of Animal Science 81, 2419-2424.

Mesa H, Safranski TJ, Cammack KM, Weaber RL and Lamberson WR 2006. Genetic and phenotypic relationships of farrowing and weaning survival to birth and placental weights in pigs. Journal of Animal Science 84, 32-40.

Pedersen LJ, Jørgensen E, Heiskanen T and Damm BI 2006. Early piglet mortality in loose-housed sows related to sow and piglet behaviour and to the progress of parturition. Applied Animal Behaviour Science 96, 215-232.

Pejsak Z 1984. Some pharmacological methods to reduce intrapartum death of piglets. Pig News Information 5, 35-37.

Perry JS 1954. Parturition in the pig. Veterinary Record 66, 706-709.

Randall GCB 1972a. Observations on parturition in sow. I. Factors associated with the delivery of the piglets and their subsequent behaviour. Veterinary Record 90, 178-182.

Randall GCB 1972b. Observations on parturition in sow. II. Factors influencing stillbirth and perinatal mortality. Veterinary Record 90, 183-186.

Rydhmer L and Lundeheim N 2005. When to farrow? Genetic correlation between gestation length and piglet survival. Proceedings of the 56 th annual meeting of the European Association for Animal Production, Uppsala, Sweden, G4. Statistical Analysis Systems Institute 2001. Version 5.2. SAS Institute Inc., Cary, NC, USA.

Sims LD and Glastonburry JRW 1996. Neonatal mortality. In Pathology of the pig. A diagnostic guide (ed. LD Sims and JRW Glastonbury), pp. 423-432. The Pig Research and Development Corporation, Barton.

Smith C 1977. Use of stored frozen semen and embryos to measure genetic trends in farm livestock. Zeitschrift für Tierzüchtung und Züchtgsbiologie 94, 119-127.

Svendsen J, Svendsen LS and Bengtsson AC 1986. Reducing perinatal mortality in pigs. In Diseases of swine (ed. AD Leman, B Straw, D Glock, WL Mengeling, RHC Penny and E Scholl), pp. 813-825. lowa State University Press, Ames, IA. Tribout T, Langant H, Caritez JC, Gogué J, Gruand J, Guéblez R, Labroue F and Bidanel JP 2001. Estimation, par utilisation de semence congelée, du progrès génétique réalisé en France entre 1977 et 1998 dans la race porcine Large White. Dispositif expérimental et premiers résultats. Journées de la Recherche Porcine en France 33, 119-125. 
Tribout T, Caritez JC, Gogué J, Gruand J, Billon Y, Bouffaud M, Lagant H, Le Dividich J, Thomas F, Quesnel H, Guéblez R and Bidanel JP 2003. Estimation, par utilisation de semence congelée, du progrès génétique réalisé en France entre 1977 et 1998 dans la race porcine Large White: résultats pour quelques caractères de reproduction femelle. Journées de la Recherche Porcine en France $35,285-292$.

Vallet JL 2000. Fetal erythropoiesis and other factors which influence uterine capacity in swine. Journal of Applied Animal Research 17, 1-26.
Vallet JL, Leymaster KA and Christenson RK 2002. The influence of uterine function on embryonic and fetal survival. Journal of Animal Science 80 (E. Suppl. 2), E115-E125.

Van der Lende T, Van Rens BTTM and Leenhouwers JI 2000. Biological and genetic aspects of pre- and perinatal mortality in swine. $5^{\circ}$ Seminario Internacional de Suinocultura, Expo Center Norte, SP.

Vangen 0 1972. Mortality in two different lines of pigs selected for rate of gain and thickness of backfat. Acta Agriculturae Scandinavica 22, 238-242. 